University of South Carolina

Scholar Commons

\title{
Parental Report Versus Child Perception of Familial Support: Which Is More Associated With Child Physical Activity and Television Use?
}

\author{
Daheia J. Barr-Anderson \\ University of South Carolina - Columbia, barra027@umn.edu \\ Ramona Robinson-O'Brien \\ Jess Haines \\ Peter J. Hannan \\ Dianne R. Neumark-Sztainer
}

Follow this and additional works at: https://scholarcommons.sc.edu/

sph_epidemiology_biostatistics_facpub

Part of the Public Health Commons

Publication Info

Published in Journal of Physical Activity and Health, Volume 7, Issue 3, 2010, pages 364-368.

Barr-Anderson, D. J., Robinson-O'Brien, R., Haines, J., Hannan, P., \& Neumark-Sztainer, D. (2010). Parental report versus child perception of familial support: Which is more associated with child physical activity and television use? Journal of Physical Activity and Health, 7(3), 364-368.

(c) Journal of Physical Activity and Health, 2010, Human Kinetics

This Article is brought to you by the Epidemiology and Biostatistics at Scholar Commons. It has been accepted for inclusion in Faculty Publications by an authorized administrator of Scholar Commons. For more information, please contact digres@mailbox.sc.edu. 


\title{
Parental Report Versus Child Perception of Familial Support: Which Is More Associated With Child Physical Activity and Television Use?
}

\author{
Daheia J. Barr-Anderson, Ramona Robinson-O’Brien, Jess Haines, \\ Peter Hannan, and Dianne Neumark-Sztainer
}

\begin{abstract}
Background: Parent-report and child perception of familial support for weight-related behaviors may not be congruent. This research explores whether parent-report or child perception is more strongly associated with child-reported physical activity and television (TV) use. Methods: Elementary school children (n = 73) participating in Ready. Set. ACTION!, a theater-based obesity prevention pilot program in Saint Paul, $\mathrm{MN}$, and their parents completed surveys assessing familial support for physical activity and limitations on TV use in fall 2006. Paired $t$ tests examined congruency between parent-report and child perception. Linear regression models adjusted for sociodemographics explored the associations between familial support and child-reported behavior. Results: Levels of agreement between parent-report and child perception for support for physical activity and limitations on TV use were approximately $70 \%$. Compared with parent-report for physical activity support, child perception was more strongly associated with child physical activity $(\beta=$ $.17, P=.02)$. Neither parent-report nor child perception for support for limitations on TV use was associated with child TV use. Discussion: Although parent-report and child perception of familial support for physical activity and to limit TV use were similar, child perception was more strongly associated with child physical activity behavior. More research, probably qualitative, is needed to examine how parents and children define and perceive parental support.
\end{abstract}

Keywords: parent-child agreement, psychosocial, influence

Familial support for physical activity has been found to be associated with increased physical activity in children, ${ }^{1,2}$ but it is inconclusive whether familial support to limit sedentary behaviors, such as television (TV) use, is associated with decreased sedentary behavior. ${ }^{2}$ When examining associations between environmental and social factors and children's behavior, there may be a question of whether to collect data from parents, children, or both. There is evidence that parental report and child perception of familial support for other weight-related behaviors, such as dieting, may differ and that child perception may be more predictive of child behavior than parental report. ${ }^{3}$ Research exploring perceptions of familial support for physical activity or limitation on TV use has typically used parent or child self-report. However, to the best of

Barr-Anderson is with the School of Kinesiology, University of Minnesota, Minneapolis, MN. Robinson-O'Brien is with the Nutrition Dept, College of Saint Benedict \& St. John's University, Saint Joseph, MN. Haines is with the Dept of Ambulatory Care and Prevention, Harvard Medical School/Harvard Pilgrim Health Care, Boston, MA. Hannan and Neumark-Sztainer are with the Division of Epidemiology and Community Health, University of Minnesota, Minneapolis, MN.. our knowledge research has not compared parental and child report of familial support. In addition, it is unknown whether parent or child report of familial support is more strongly associated with child physical activity and sedentary behavior. In providing advice to parents, and in the development of interventions aimed at increasing child physical activity and decreasing sedentary activity, it is important to better understand the potential role of parents in supporting their children's behaviors.

The aim of this study is 1) to compare parental report and child perception of familial support for child's physical activity and limitations on child TV use and 2) to determine whether parental report or child perception is more strongly associated with child physical activity and TV use.

\section{Methods}

\section{Selection and Description of Participants}

The current study's population included 73 4th through 6 th grade children ( 55 girls and 18 boys) who participated in Ready. Set. ACTION! pilot program, a theater-based, obesity prevention intervention. ${ }^{4}$ Data from 1 of the 
parents or other primary caregiver of each child were also collected.

Children were recruited from 4 urban elementary schools in St. Paul, MN that serve primarily low-income populations; approximately $90 \%$ of the students at each school qualify for free or reduced lunch. The mean age of the children was $10.1 \pm 1.1$ years and the majority of the sample self-identified as a racial/ethnic minority: $58 \%$ non-Hispanic black, $11 \%$ Asian/Hmong, $8 \%$ nonHispanic white, $3 \%$ Hispanic, and 20\% mixed/other. Forty-three percent of the children were overweight or obese with a body mass index (BMI) values greater than or equal to 85th percentile for age and sex. More than $80 \%$ of the parent/primary caregiver sample was female.

Written consent was obtained from parents/primary caregivers for their own participation in the study, as well as for their child to participate in the study. Children signed a written assent form. Ethical approval for this study was received from the Institutional Review Board of the University of Minnesota and the Saint Paul Schools Research Committee.

\section{Technical Information}

The development of the child and parent surveys was guided by the Social Cognitive Theory, ${ }^{5}$ a review of existing instruments, ${ }^{6-10}$ and a pilot test of the student survey. Parents or primary caregivers provided written consent for their participation and their child's participation in the study. Children also signed a written assent form. Ethical approval for this study was received from the University of Minnesota Institutional Review Board. Measures assessed on the child and parent surveys used in the current analyses are described in Table 1.

\section{Statistics}

For each of the 7 items used to assess family support for the child's physical activity (5 items) and limitations on TV use (2 items), the percentages of children and parents responding in the 2 higher categories ("almost every day" and "every day") were calculated; these percentages were compared using paired $t$ tests to identify any differences between parental report and child perception of familial support. We also calculated a level of agreement of response among parent-child dyads, if child and parent differed by 1 or fewer response options on a 4-point Likert scale. This is a measure of consistency between parent and child response, which is a superior measure than exact agreement because of the multiple categories for the 2 scales of family support for physical activity and TV.

Linear regression modeling was used to examine whether child or parent perception of familial support was more strongly associated with child's level of physical activity and TV use measured on a continuum of hours per week. We ran separate models for physical activity and TV use. Child's race/ethnicity (black/other), gender, and parental education were also included in all regression models. All p-values were two-sided, with $P$
$<.05$ considered statistically significant. Analyses were conducted using SAS software (version 8.2; SAS Institute Inc., Cary, NC).

\section{Results}

Children reported a weekly mean of $4.3 \pm 2.6$ hours of moderate-to-vigorous physical activity and $15.5 \pm$ 12.1 hours of TV use. Approximately $70 \%$ of parentchild pairs reported a similar level of family support for physical activity and for limitations on child TV use. The average exact agreement is $33 \%$, ranging from $25 \%$ to $42 \%$. Table 2 displays the level of good agreement, which ranged from $62 \%$ to $78 \%$. Despite the relatively high level of good agreement, there were also some noteworthy differences in child and parent report of family support. For example, a greater percentage of children than parents reported high levels of family support for child physical activity ( $51 \%$ vs $38 \%, P<.01$; Table 2$)$. More specifically, a greater percentage of children compared with parents reported that parents provided high levels of support by doing physical activities with the child $(40 \%$ vs $21 \% ; P<.01)$ and by providing transportation to physical activity opportunities ( $45 \%$ vs $24 \% ; P<.01)$. Similar proportions of parents and children reported high levels of family support to limit TV use and to encourage watching less TV $(P>.05)$.

After adjusting for sociodemographic variables, child perception, but not parental report, of family support for child physical activity was positively associated with the self-reported child physical activity (Table 3) (child perception: $\beta=.17, \mathrm{SE}=.071, R^{2}=22.9 \%, P=$ .02 ; parental report: $\beta=-.11, \mathrm{SE}=.095, R^{2}=18.0 \%$, $P>.05)$. Neither child perception nor parental report of family support to limit child TV use was associated with child TV use.

\section{Discussion}

As compared with parents, a higher proportion of children in this study viewed their home environment as supportive for being physically active and limiting TV use. The relatively high level of agreement for family support $(70 \%)$ between parent-child dyads suggests that most pairs shared similar perceptions on the level of support offered to the child to increase physical activity and decrease TV use. The high level of congruence, along with the finding that when there were differences, children were more likely to report a supportive home environment than parents, suggest that parents may not be exaggerating or over-reporting, due to social desirability, the support they give to their child.

Although parent and child perceptions are more similar than dissimilar, there is still a substantial level of discordance (approximately 30\%) that is worth noting. Interestingly, children were more likely to report a supportive home environment than their parents. Small 
Table 1 Description of Child and Parent Reported Measures

\begin{tabular}{|c|c|}
\hline Construct/variable & Description of assessment \\
\hline \multicolumn{2}{|l|}{ Child demographics } \\
\hline Ethnicity & Are you Hispanic or Latino? 1) yes; 2) no \\
\hline Race & $\begin{array}{l}\text { Do you think of yourself as (you may select more than one): 1) White; 2) Black/African-Ameri- } \\
\text { can; 3) Asian-American; 4) Hmong; 5) American-Indian; 6) Other }\end{array}$ \\
\hline Age & $\begin{array}{l}\text { How old are you? 1) } 8 \text { years old; 2) } 9 \text { years old; 3) } 10 \text { years old; 4) } 11 \text { years old; 5) } 12 \text { years } \\
\text { old; 6) } 13 \text { years old }\end{array}$ \\
\hline Body mass index (BMI) & $\begin{array}{l}\text { Height and weight measures were assessed by trained research staff using standardized equip- } \\
\text { ment and procedures. Age and sex-specific BMI z-scores were calculated based on the Center } \\
\text { for Disease Control growth charts, which are age and sex specific. }\end{array}$ \\
\hline \multicolumn{2}{|l|}{ Behaviors* } \\
\hline \multirow[t]{6}{*}{ Physical activity } & In the past week, how many hours did you spend doing the following activities: \\
\hline & $\begin{array}{l}\text { 1) Hard/strenuous exercise: examples biking fast, running, jogging, swimming laps, soccer, } \\
\text { basketball }\end{array}$ \\
\hline & 2) Moderate exercise: examples walking quickly, dancing, baseball, gymnastics, easy bicycling \\
\hline & 3) Mild exercise: examples walking slowly, bowling, stretching, household chores \\
\hline & $\begin{array}{l}\text { Response categories: 1) none; 2) } 1 \text { hour; 3) } 2 \text { hours; 4) } 3 \text { hours; 5) } 4 \text { hours; 6) } 5 \text { hours; 7) } 6 \text { or } \\
\text { more hours }\end{array}$ \\
\hline & $\begin{array}{l}\text { (Adapted from Godin and Shephard). }{ }^{11} \text { Test-retest }=0.63 \text { (hard/strenuous); } 0.52 \text { (moderate); } \\
0.51 \text { (mild); } 0.69 \text { (total time per week) }\end{array}$ \\
\hline \multirow[t]{3}{*}{ Television use } & $\begin{array}{l}\text { On } 1 \text { average weekday, how many hours do you spend watching TV/videos/ DVDs: 1) } 0 \text { hour; } \\
\text { 2) } 1 \text { hour; 3) } 2 \text { hours; 4) } 3 \text { hours; 5) } 4 \text { hours; 6) } 5 \text { hours; 7) } 6+\text { hours }\end{array}$ \\
\hline & A similar question was asked about average Saturday or Sunday. \\
\hline & $\begin{array}{l}\text { (Adapted from McGuire et. al). }{ }^{12} \text { Test-retest for weekday use }=0.80 . \text { Test-retest for weekend } \\
\text { use }=0.69\end{array}$ \\
\hline \multicolumn{2}{|l|}{ Perceptions of family support ${ }^{1}$} \\
\hline \multirow{9}{*}{$\begin{array}{l}\text { Perceived family support } \\
\text { for physical activity } \\
\text { (5-item scale) }\end{array}$} & $\begin{array}{l}\text { During a typical week, how often has a member of your household (for example, your mother, } \\
\text { father, sister, grandparent, or other relative): }\end{array}$ \\
\hline & 1) Encouraged you to do physical activities or play sports? (encouraged activity) \\
\hline & 2) Done a physical activity or played sports with you? (done activity together) \\
\hline & $\begin{array}{l}\text { 3) Provided transportation to a place where you can do physical activities or sports? (provided } \\
\text { transportation) }\end{array}$ \\
\hline & 4) Watched you participate in physical activities or sports? (watched participation) \\
\hline & 5) Told you that you are doing well in physical activities or sports? (doing well) \\
\hline & Response categories: 1) not at all; 2) sometimes; 3) almost every day; 4) every day \\
\hline & (Adapted from Prochaska, Rogers, and Sallis). ${ }^{13}$ \\
\hline & $\begin{array}{l}\text { Parental report: test-retest }=0.81 \text {, Cronbach's } \alpha=0.78 \text {; Child perception: test-retest }=0.88 \text {; } \\
\text { Cronbach's } \alpha=0.86\end{array}$ \\
\hline \multirow{6}{*}{$\begin{array}{l}\text { Perceived family support } \\
\text { to limit/reduce television } \\
\text { use (2-item scale) }\end{array}$} & $\begin{array}{l}\text { During a typical week, how often has a member of your household (for example, your mother, } \\
\text { father, sister, grandparent, or other relative): }\end{array}$ \\
\hline & 1) Limited the amount of time you can watch TV? (limited TV) \\
\hline & 2) Encouraged you to watch less TV? (encouraged less TV) \\
\hline & Response categories: 1) not at all; 2) sometimes; 3) almost every day; 4) every day \\
\hline & (Adapted from Prochaska, Rogers, and Sallis). ${ }^{13}$ \\
\hline & $\begin{array}{l}\text { Parental report: test-retest }=0.81 \text {, Cronbach's } \alpha=0.64 \text {; Child perception: test-retest }=0.88 \text {; } \\
\text { Cronbach's } \alpha=0.64\end{array}$ \\
\hline
\end{tabular}

* These variables were assessed via child and parent report. Child survey items are provided; similar items were used on parent survey with minor wording modifications. 
Table 2 Percentages of Parents and Children Reporting High Levels of Family Support for Child's Physical Activity and Family Support to Limit Child's Television Use Across Parent-Child Dyads

\begin{tabular}{lcccc}
\hline & $\begin{array}{c}\text { Child } \\
(\mathbf{n = 7 3}) \%\end{array}$ & $\begin{array}{c}\text { Parent } \\
(\mathbf{n}=\mathbf{7 3}) \%\end{array}$ & $\begin{array}{c}\text { Paired } \boldsymbol{t} \text { test } \\
\boldsymbol{P} \text {-value }\end{array}$ & $\begin{array}{c}\text { Good agreement } \\
\text { across dyads } \%\end{array}$ \\
\hline Perceived family support for child's physical activity & 51 & 38 & $<.01$ & 66 \\
Encouraged activity & 54 & 51 & $\mathrm{NS}$ & 78 \\
Done activity together & $\mathbf{4 0}$ & $\mathbf{2 1}$ & $<.01$ & 74 \\
Provided transportation & $\mathbf{4 5}$ & $\mathbf{2 4}$ & $<. \mathbf{0 1}$ & 68 \\
Watched participation & 41 & 30 & $\mathrm{NS}$ & 63 \\
Doing well & 46 & 49 & $\mathrm{NS}$ & 73 \\
Perceived family support to limit child's television use & 40 & 41 & $\mathrm{NS}$ & 66 \\
Limited TV & 35 & 44 & $\mathrm{NS}$ & 69 \\
Encouraged less TV & 54 & 53 & $\mathrm{NS}$ & 62 \\
\hline
\end{tabular}

* Good agreement describes exact agreement or agreement within 1 category on the 4-point Likert scale. The average exact agreement is $33 \%$, ranging from 25 to $42 \%$.

Table 3 Association Between Parental Report and Child Perceptions of Familial Support With Child's Physical Activity and Television Use ${ }^{a}$

\begin{tabular}{|c|c|c|c|c|c|c|}
\hline & \multicolumn{2}{|c|}{ Parental report } & \multirow[b]{2}{*}{$P$} & \multicolumn{2}{|c|}{ Child perception } & \multirow[b]{2}{*}{$P$} \\
\hline & $\beta$ (SE) & $\mathbf{R}^{2}$ & & $\beta$ (SE) & $\mathbf{R}^{2}$ & \\
\hline Perceived family support for child's physical activity & $-.11(.095)$ & .180 & NS & $.17 *(.071)$ & .229 & .02 \\
\hline Perceived family support to limit child's TV use & $-.59(.933)$ & .055 & NS & $-.01(.819)$ & .049 & NS \\
\hline
\end{tabular}

${ }^{a}$ Models are adjusted for race/ethnicity, gender, and parental education.

actions of support (ie, encouraging words, providing rides to and from practice) may be viewed by parents as part of their parental duties, but positively viewed by children as their parents supporting them.

Compared with parental report, child perception for familial support was more strongly associated with child physical activity behavior. This may indicate that child perception may be more important than what parents perceive about their child's behavior. Our results highlight the importance of recognizing potential differences that may exist between parent and child perceptions of parental support for physical activity and limitations on child TV use. Qualitative research examining how parents and children define and perceive parental support may help inform the development of valid measures of parental influences.

This study provides preliminary examination of both parental report and child perception of familial support and how they contribute to child's behavior related to physical activity and TV use. A unique aspect of the current study is that both parental report and child perception were used to examine the relationship between familial support and child's physical activity and TV use. However, in interpreting the findings, it is important to note that both child perception of familial support and child's behavior were based on data gathered from one person (ie, child). In contrast, when examining the parental perception of familial support with child's behavior, information was ascertained from both the parent and child. It is possible that more measurement error was introduced when examining parental perception of support with child's behavior because data were drawn from 2 different sources. Limitations of this study are the cross-sectional study design, self-reported questionnaire, the brief survey questions to assess parental and child perceptions and child behavior, and the small sample size that did not allow for stratifications by gender or race. Despite these limitations, to the authors' knowledge, no similar work has been published. Future research should build on these preliminary findings and explore the role of parental report and child perceptions for familial support on child's behavior through qualitative exploration and quantitatively in larger sample sizes using more objective measures of physical activity and TV use.

\section{Acknowledgments}

This study was supported by grant R21 DK072972 (PI: Neumark-Sztainer) from the National Institute of Diabetes and Digestive and Kidney Diseases. The first author's time was supported by the Adolescent Health Protection Research Training grant number T01-DP000112 (PI: Bearinger) from the Centers 
for Disease Control and Prevention, Department of Health and Human Services. The authors have no disclaimers to disclose and there is no conflict of interest for any of the authors.

\section{References}

1. Sallis JF, Prochaska JJ, Taylor WC. A review of correlates of physical activity of children and adolescents. Med Sci Sports Exerc. 2000;32:963-975.

2. Van Der Horst K, Paw MJ, Twisk JW, Van Mechelen W. A brief review on correlates of physical activity and sedentariness in youth. Med Sci Sports Exerc. 2007;39:12411250 .

3. Haines J, Neumark-Sztainer D, Hannan P, RobinsonO'Brien R. Child versus parent report of parental influences on children's weight-related attitudes and behaviors. J Pediatr Psychol. 2008;33:783-788.

4. Neumark-Sztainer D, Haines J, Robinson-O'Brien R, et al. 'Ready. Set. ACTION!' A theater-based obesity prevention program for children: a feasibility study. Health Educ Res; 2009;24:407-420.

5. Bandura A. Social Foundations of Thought and Action: A Social Cognitive Theory. Englewood Cliffs, NJ: PrenticeHall; 1986.

6. Baranowski T, Baranowski J, Cullen KW, et al. 5 a day achievement badge for African-American boy scouts: pilot outcome results. Prev Med. 2002;34:353-363.
7. Haines J, Neumark-Sztainer D, Perry CL, Hannan PJ, Levine MP. V.I.K. (Very Important Kids): a school-based program designed to reduce teasing and unhealthy weightcontrol behaviors. Health Educ Res. 2006;21:884-895.

8. Neumark-Sztainer D, Sherwood NE, Coller T, Hannan PJ. Primary prevention of disordered eating among preadolescent girls: feasibility and short-term effect of a communitybased intervention. J Am Diet Assoc. 2000;100:1466-1473.

9. Neumark-Sztainer D, Story M, Hannan PJ, Rex J. New Moves: a school-based obesity prevention program for adolescent girls. Prev Med. 2003;37:41-51.

10. Rochon J, Klesges RC, Story M, et al. Common design elements of the Girls Health Enrichment Multi-site Studies (GEMS). Ethn Dis. 2003;13:S6-S14.

11. Godin G, Shephard RJ. A simple method to assess exercise behavior in the community. Can J Appl Sport Sci. 1985;10:141-146.

12. McGuire MT, Hannan PJ, Neumark-Sztainer D, Cossrow NH, Story M. Parental correlates of physical activity in a racially/ethnically diverse adolescent sample. J Adolesc Health. 2002;30:253-261.

13. Prochaska JJ, Rogers MW, Sallis JF. Association of parent and peer support with adolescent physical activity. Res $Q$ Exerc Sport. 2002;73:206-210. 